\title{
'A travessia entre o pecado e a fé': as aldeias Kiriri e os escritos jesuíticos de conversão (1684-1699) 1
}

\author{
'The Crossing Between sin and faith': Kiriri villages and Jesuitical \\ conversion writings (1684-1699)
}

\author{
Ane Luise Silva Mecenas²
}

RESUMO

O presente artigo visa analisar a experiência jesuítica por meio dos impressos de normatização da língua Kiriri. No intuito de discutir as estratégias de conversão empregadas pelos missionários que atuaram junto aos Kiriri, bem como o processo de tradução cultural na segunda metade do século XVII junto às missões do sertão da Bahia. Coube aos padres da Companhia de Jesus a tutela dos índios da nação Kiriri, que se encontravam na margem sul do Rio São Francisco. Durante esse período de reordenação dos domínios coloniais e de implantação de novos aldeamentos, foi produzido um significativo corpus documental, que versa sobre a solicitação de índios, trazem notícias sobre as aldeias, descrições dos espaços e sobre a necessidade da elaboração de novos instrumentos que auxiliassem a comunicação. Para o atendimento destas solicitações, foram realizados estudos linguísticos, com o propósito de sistematizar e normatizar as línguas locais e, assim, tornar possível a comunicação e a pretendida conversão.

Palavras-chave: Jesuítas. Impressos. Kiriri. Conversão.

\section{ABSTRACT}

Or present article aims to analyze the Jesuit experience by two printed matters of Kiriri. I do not intend to discuss the strategies of conversation carried out by missionaries that took place next to Kiriri, the cultural translation process in the second half of the XVII century together with misson of bonder of Bahia. Courte Company of Jesus to guardianship two natives of Nairobi Kiriri, which is located on the São Francisco River. During this period of reordering two colonial dominions and the implantation of new villages, a significant documentary corpus was produced, dealing with the request of Indians, news about the villages, descriptions of two areas for the development of new instruments that would help a communication. For

\footnotetext{
${ }^{1}$ Esse trabalho é parte da tese defendida no Programa de Pós-Graduação em História da UNISINOS, intitulada "Trato da perpétua tormenta": A conversão nos sertões de dentro e os escritos de Luigi Vincenzo Mamiani della Rovere sobre os Kiriri (1666-1699).

${ }^{2}$ Doutora em História .Universidade do Vale do Rio dos Sinos. e-mail: anemecenas@gmail.com
} 
or assistance to these requests, we have carried out linguistic studies, with the purpose of systematizing and standardizing local languages and, as such, making possible communication to a pretended converse.

Keyword: Jesuits. Printed Kiriri. Conversion.

Ludovico Vicenzo Mamiani Della Rovere³, o autor da Gramática e do Catecismo escritos língua Kiriri, nasceu na cidade de Pésaro, na Itália, ${ }^{4}$ e passou a integrar a Companhia de Jesus no ano de 1668 (LEITE, 2004). Em 1684, antes mesmo de fazer o quarto voto e, contando, então, com trinta e dois anos, partiu de Lisboa, rumo à Bahia. Seu destino inicial na América portuguesa era a Missão do Maranhão. ${ }^{5}$

Ao final do século XVII, Mamiani publicou, com a autorização da Ordem e das instâncias metropolitanas, dois instrumentos de conversão, o Catecismo da Doutrina Christãa na Lingua Brasilica da Nação Kiriri (MAMIANI, 1942) e a Arte de Grammatica da Lingua Brasilica da naçam Kiriri (MAMIANI, 1877), que resultaram da sistematização de suas experiências como missionário junto a este grupo indígena. ${ }^{6}$ Antes de os estudos realizados pelo padre Mamiani ganharem a prensa e serem divulgados na Metrópole portuguesa, o padre João de Barros ${ }^{7}$ já havia produzido um manuscrito, que, no entanto, não chegou a ser publicado. ${ }^{8}$

Os escritos do padre Mamiani já foram objeto de estudo de alguns trabalhos.

Os estudos já realizados sobre as missões de indígenas Kiriri possuem algumas particularidades. Os trabalhos que versam sobre os aldeamentos os consideram, em sua grande maioria, a partir da lógica das Capitanias, dessa forma, eles são estudados dissociadas da lógica de ocupação dos espaços por parte dos indígenas. Exemplo disso são os estudos sobre a aldeia do Geru, que podem ser encontrados em uma produção historiográfica atrelada à História da Capitania de Sergipe Del Rey. Dentre eles, se destaca o livro História de Sergipe, (FREIRE, 1977), que debruça-se sobre uma única aldeia, a do Geru. Por se tratar de obra que busca reconstituir os primórdios da formação da Capitania de Sergipe Del Rey, discute temas

\footnotetext{
${ }^{3} \mathrm{Na}$ documentação, padre Mamiani aparece registrado de várias formas, dentre as quais detacamos: Luiz Vicencio Mamiani, Luiz Mamiani, Ludovico Mamiani ou Ludovico Vicenzo Mamiani Della Rovere.

${ }^{4}$ No período em questão, Pésaro fazia parte do Reino de Nápoles, visto que a delimitação territorial atual se deu no século XIX, com a Unificação Italiana, cujos desdobramentos se estenderam até o século XX, com a Questão Romana, nos idos de 1929.

${ }^{5}$ Após consulta à documentação, não foi possível identificar o motivo da mudança do destino do padre Mamiani. $\mathrm{O}$ mês de sua chegada não é apresentado nos registros. Contudo, é importante salientar que no começo do ano de 1684, em São Luís, estava ocorrendo o segundo levante contra a atuação dos jesuítas. No primeiro levante, no ano de 1661, o colégio Nossa Senhora da Luz foi invadido e alguns padres foram encaminhados para a Metrópole. Vinte e três anos depois, um novo levante ocorre na cidade, a Revolta de Beckman. Foram apresentados como motivos de insatisfação, a miséria, a cobiça dos padres da Companhia de Jesus e o não atendimento das demandas da população pela Coroa portuguesa. (CHAMBOULEYRON, 2015).

${ }^{6}$ Diferentemente do que Pompa afirmou em relação às duas obras do padre Mamiani, primeiro ocorreu a publicação do Catecismo e, depois, a da Gramática.(POMPA, 2003, p. 86).

${ }^{7}$ Segundo Serafim Leite, o padre João de Barros era natural de Lisboa e atuou nas aldeias de Canabrava, Saco dos Morcegos e Natuba. Ingressou na Companhia em 1654 e estudou latim no Colégio de São Paulo em 1659. Nos idos de 1667, junto com o padre Jacob Rolando, iniciaram a conversão de índios Kiriri na aldeia de Natuba. (LEITE, 2003, p. 287).

${ }^{8}$ Na parte dedicada "Ao leytor", o padre Mamini ressalta a necessidade da publicação para o melhor conhecimento da língua, que muito favoreceria e asseguraria o êxito do processo de catequese. Contudo, de acordo com Leite, o Catálogo de 1679 faz referência a um Vocabulário e um Catecismo Kiriri produzido por João de Barros. Por não haver informações sobre a publicação desta obra,é possível que os dois escritos circulassem como manuscritos à epoca. (LEITE, 2003, p. 232).
} 
referentes à administração local, à doação de sesmarias, ao papel dos criadores de gado e à presença jesuítica atrelada à conquista da localidade nos marcos iniciais da colonização 1575 e 1590. De acordo com Freire, antes mesmo do aldeamento, os índios do Geru já participavam de incursões com os portugueses para o apresamento de escravos fugidos e também para a procura das minas de prata na Serra de Itabaiana. ${ }^{9}$

Também Serafim Leite, no livro História da Companhia de Jesus, apresenta, a partir de uma significativa documentação, principalmente daquela encontrada no ARSI, o período inicial da presença dos religiosos da ordem nas referidas aldeias de forma isolada, evidenciando as dificuldades enfrentadas nas conquistas desses índios e os feitos na administração do "remédio às almas". (LEITE, 1945).

O processo de conversão dos Kiriri foi também abordado por Beatriz Gois Dantas (1973), que relaciona diversas fontes e, através delas, consegue preencher algumas das lacunas existentes sobre a Missão do Geru. Seguindo os passos do estudo de Dantas, Pedro Santana (2004), embasado nas fontes publicadas na coleção Documentos Históricos, também aborda os aldeamentos indígenas localizados na Capitania de Sergipe Del Rey. Já Maria Thetis Nunes (1996) elaborou dois livros, nos quais discute Sergipe colonial, apresentando um panorama das inúmeras facetas do processo de colonização, a partir de um substancial conjunto de fontes.

A dinâmica dos aldeamentos foi também analisada no período que se sucedeu à expulsão jesuítica. É o caso do trabalho Fabricio Lyrio Santos (2014), intitulado "Da catequese à civilização", que busca analisar os desdobramentos da aplicação do Alvará de 8 de maio de 1758, quando as então aldeias foram elevadas à condição de vila. Outra contribuição dos estudos de Fabricio Lyrio é a de analisar diferentes comunidades indígenas da Bahia e não apenas os Kiriri.

Estes estudos mais recentes têm levado em conta as particularidades de cada uma destas aldeias, as negociações e as alianças que estabeleceram e, ainda, as diversas manifestações de resistência desses indígenas, desconstruindo uma visão única sobre os Tapuia que foi tecida ao longo do processo de conquista e difundida pela historiografia. Essa é, sem dúvida, uma das perspectivas de análise que devem ser, segundo nosso entendimento, adotadas para a compreensão do universo Kiriri, na medida em que estes indígenas são percebidos como sujeitos históricos e inseridos numa complexa teia de negociações. Esclarecemos que, apesar de nos identificarmos e compartilharmos dos pressupostos teórico-metodológicos da Nova História Indígena, eles não foram o fio condutor na análise das fontes que selecionamos.

\footnotetext{
${ }^{9}$ As incursões às minas foram rejeitadas pela coroa, em 1750 , em decorrência da proximidade com o litoral, na tentativa de evitar uma busca desenfreada por minérios e o desaquecimento da produção de Sergipe, principalmente o fornecimento de gado que abastecia a economia da Bahia, conforme aponta (RUSSEL-WOOD, 1999, p. 475).
} 
Considerando que o domínio dos dialetos Kiriri foi fundamental para o processo de conversão, alguns pesquisadores têm procurado também compreender a lógica linguística deste grupo indígena, a partir da análise dos catecismos e gramáticas que foram escritos pelos missionários.(AGNOLIN, 2007; MARIANI, 2004; NUNES, 2006). Inserimo-nos nesta abordagem, na medida em que nos propomos a analisar uma dessas gramáticas e um desses catecismos, procurando, também reconstituir os caminhos percorridos pelos dois impressos, desde o momento em que foram escritos nas aldeias Kiriri até sua impressão em Lisboa.

A primeira edição da Gramática é de 1698 e, a do Catecismo, de 1699. No século XIX, no contexto de reedição de várias obras deste gênero produzidas na América, foi organizada a publicação da segunda edição da Gramática de Mamiani. Mas, somente no século XX, a Biblioteca Nacional do Rio de Janeiro organizou uma edição fac-similar do Catecismo. Poucos foram os exemplares da primeira edição que localizamos, no entanto, optamos por priorizar a análise da primeira edição, cotejando-a, sempre que possível, com a segunda edição.

Quanto à circulação das obras de Mamiani, sabe-se que a partir do século XIX, elas foram reeditadas. Isto, em grande medida decorreu da formação do campo da antropologia como disciplina autônoma que passou a se dedicar ao estudo das sociedades tidas como "primitivas", das pesquisas envolvendo o mundo simbólico da magia e da religião, bem como da reedição de obras que versavam sobre as línguas indígenas. ${ }^{10}$ Já no século $\mathrm{XX}$, os anos do governo Vargas foram caracterizados por uma política nacionalista, com atuação em diversas frentes, inclusive, em relação ao patrimônio material, com a criação do SPHAN e, também, através da publicação de obras sobre línguas indígenas (FONSECA, 2005). Na década de 1940, os textos de Mamiani passaram a constar em todas as bibliografias que se referiam à língua indígena (BANDEIRA, 1972), em obras de historiadores ${ }^{11}$ e de antropólogos e, também, em manuais de História da Educação.

Apesar desse significativo conjunto de estudos que versam acerca de diferentes aspectos dos escritos do padre Mamiani, esse artigo busca apresentar ao leitor uma originalidade ao trabalho por meio do recorte interpretativo, o qual se encontra delimitado por meio do que o autor destaca como os "inimigos da alma": o mundo, o diabo e a carne. Como também o cotejo com o Catecismo de língua Kariri de autoria do capuchinho Bernardo de Nantes e o Itinerário para os párocos dos índios do padre Peña Montenegro.

Ao longo de quase duas décadas, suas atividades como missionário se circunscreveram à outra região, a aldeia do Geru, na então Capitania de Sergipe del Rey. A sua ida para esse aldeamento contribuiu para a constituição de um novo capítulo na catequese do sertão, uma vez que este missionário buscou solucionar um problema já identificado por outros jesuítas

${ }^{10}$ No século XIX, na Alemanha, o bibliófilo de línguas americanas Julio Platzmann foi responsável pela publicação de um conjunto de catecismos jesuíticos produzidos na América, dentre os quais se destacam as obras do padre Mamiani, de Ruiz de Montoya e de Anchieta. Platzmann doou as pranchas das duas obras à Biblioteca Nacional do Rio do Janeiro.

${ }^{11}$ Ver os estudos de Felisbelo Freire (1977) Serafim Leite (1945) Beatriz Gois Dantas (1973). Maria Thetis Nunes (1996), Cristina Pompa (2003), Nunes (2006). 
desde as primeiras tentativas de conversão dos Kiriri ${ }^{12}$ : a dificuldade de compreensão da língua que este grupo indígena falava.

Mamiani viveu com grande compromisso sua atividade missionária na aldeia do Geru, dedicando especial atenção à comunicação entre os religiosos e os índios, razão pela qual se dedicou ao estudo e à sistematização do idioma dos nativos. O Catecismo publicado em Lisboa, no ano de 1698, foi dividido em três seções: a primeira traz os rudimentos da fé e da oração, a segunda parte apresenta os mistérios, os mandamentos e os sacramentos e, por fim, a terceira seção consiste em uma série de recomendações para os evangelizadores, como as relativas à preparação dos índios para receber os sacramentos ou para a confissão.

Já a Arte da Gramática da língua Brazilica da Nação Kiriri está estruturada em duas seções: a primeira é dedicada à ortografia, pronúncia, a conjugação e declinação dos nomes dos verbos; enquanto que a segunda trata da sintaxe da construção da fala, seguida por um vocabulário essencial. A obra foi traduzida para o alemão em 1852, com o título de Kiriri Grammatik der Sprache, e publicada em Leipzig. Foi a doação das pranchas desta segunda edição à Biblioteca Nacional do Rio de Janeiro que tornou possível a nova edição em português no ano de 1877.

Além destas duas obras, Mamiani produziu também outro documento, datado de 1701, e que consiste de um parecer sobre o governo temporal do Colégio de São de Paulo. Após visitar o colégio, expôs seu ponto de vista em um memorial dirigido ao Provincial Francisco de Matos, no qual não somente abordou os problemas afetos à gestão, mas também a questão da exploração do trabalho indígena (ZERON; VELLOSO, 2015).

De volta à Europa, Mamiani deu por encerrada sua condição de "viajante-tradutor" (HARTOG, 2004, p. 23), uma vez que não se dedicou mais a escrever sobre as experiências vividas nas aldeias Kiriri. Ele se estabeleceu em Roma, na casa professa da Companhia, e, em 1706, publicou Concordia doctrinae probabilistarum. Cum doctrina probabilioristarum, uma densa análise de teologia moral cuja segunda edição foi publicada dois anos depois. ${ }^{13} \mathrm{Em} 1708$, ele publicou a tradução do português para o italiano de Sermões Quaresmais, de Antônio Vieira, impresso simultaneamente em Roma e Veneza. Sabe-se, também, que exerceu o cargo de advogado da Assistência de Portugal, e que seus trabalhos posteriores abordaram as missões

\footnotetext{
${ }^{12}$ Dos registros do período colonial aos clássicos da historiografia brasileira, constata-se a simplificação da complexidade dos grupos indígenas da América portuguesa, como se pode constatar na sua divisão em dois grandes grupos: os Tupi-guarani, que viviam no litoral, e os tapuias, que habitavam o sertão. Os Kiriri foram tidos como tapuias, pois ocupavam o sertão do atual Ceará até a Paraíba, fazendo-se presente também no sul e submédio do Rio São Francisco, nos atuais estados de Alagoas, Bahia e Sergipe. Conforme Dantas (1973, p. 2), os Kiriri são “índios que formavam importante grupo linguístico cultural do Nordeste brasileiro, cujo habitat se estendia desde o Paraguassu e o rio de São Francisco até o Itapirucu, afastado da linha da costa, domínio dos povos de língua Tupi". Maria Celestino de Almeida também faz referência ao grupo: "Do tronco linguístico macro-jê e habitantes do sertão do São Francisco, os kariris (sic) tiveram seus costumes descritos por jesuítas e capuchinhos [...]". (ALMEIDA, 2010, p. 32).

${ }^{13} \mathrm{O}$ tema central desta obra é o probabilismo, muito criticado por B. Pascal e pelos jansenistas.
} 
orientais e os ritos chineses, como se pode constatar em um documento produzido um ano antes de morrer, em Roma, a 08 de março de 1730.

Se os caminhos percorridos pelos manuscritos até se tornarem impressos podem ser reconstituídos mediante a análise de sua apresentação formal e estética, das intervenções feitas pelos tipógrafos e das licenças e censuras que receberam, o contextos de sua produção e as experiências vividas por seus autores também são fundamentais para a identificação das escolhas que fizeram e que interferiram na escrita.

Desde os primórdios da colonização, os jesuítas estiveram envolvidos na adoção de estratégias de aproximação que facilitassem a comunicação com os nativos e na elaboração de catecismos, como salientado por Castelnau-L'Estoile. Estas obras, aliás, têm relação com os Exercícios Espirituais escritos pelo fundador da Ordem, Inácio de Loyola, com o Plano de Conversão do Gentio, do padre Nóbrega, e com as orientações resultantes da Visita do Pe. Christóvão de Gouvea (CASTELNAU-L'ESTOILE, 2006).

Mas, para além das regras emanadas do Estado português e da própria ordem, é preciso considerar que foi a experiência na aldeia, atrelada ao longo período de contato com os índios que possibilitou a sistematização das línguas indígenas pelos missionários. No caso de Mamiani, não seria diferente. À sua experiência, se somariam a de missionários que o antecederam no trabalho missionário junto aos Kiriri e, ainda, os modelos de gramáticas vigentes, que se adequavam à prática de escrita do Setecentos, como se poderá observar na sua organização, e conforme descreveu o capuchinho Martinho de Nantes:

[...] todos os nossos missionários entre os cariris se empenharam em aprender a sua língua, sem o uso da qual era impossível transformá-los em verdadeiros cristão, pois que é natural do bábaro a barbaria. Seriam macacos para imitar o que vissem fazer ou papagaios para repetir o que lhes ensinarem, mesmo sem o compreender, e, por consequinte, sem fé e sem conhecimento de que deviam saber. Tendo chegado antes de todos a essas nações, e cinco anos de qualquer outro missionário, fiz um dicionário da língua cariri, uma arte ou rudimento da doutrina cristã e um modelo de exame para confissão, e traduzi a vida de alguns santos, elaborando cânticos espeirtuais sobre os mistérios da fé empregando o tom dos hinos, cujo canto é mais agradável para facilitar aos missionários o uso de sua linguagem (NANTES, 1979, p. 18). 
É plausível supor que os padres da Companhia de Jesus tenham discutido estratégias e a elaboração de textos de sistematização da língua Kiriri com os capuchinhos, uma vez que a Relação de Martinho de Nantes refere a constante comunicação entre eles. Sabe-se, também, que em suas viagens a Salvador, o capuchinho costumava descansar na aldeia de Canabrava e que os jesuítas também visitaram a sua missão (NANTES, 1979).

1 -Os inimigos da alma

Ouvi: saiu o semeador a semear. Enquanto lançava a semente, uma parte caiu à beira do caminho e vieram as aves e a comeram. Outra parte caiu no pedregulho onde não havia muita terra; o grão germinou logo, porque a terra não era profunda; mas assim que o sol despontou, queimou-se e, como não tivesse raiz, secou. Outra parte caiu entre os espinhos; estes cresceram, sufocaram-na e o grão não deu fruto. Outra caiu em terra boa e deu fruto, cresceu e desenvolveu-se; um grão rendeu trinta, outro sessenta, outro cem. E dizia: Quem tem ouvidos para ouvir, ouça. $^{14}$

Em três passagens da Bíblia encontramos menção à parábola da semeadura, em Mateus 13:1-23, em Marcos 4:1-20 e em Lucas 8:4-15. No Catecismo, Mamiani retoma a parábola, renomeando os três inimigos da alma, que, segundo ele, seriam o mundo (os espinhos), o diabo (as aves) e a carne (os pedregulhos) (MAMIANI, 1698), relacionando-os com os pecados cometidos pelos índios nas aldeias. Esta associação revela que o jesuíta está em plena sintonia com a Igreja Tridentina, que reafirmava que o trabalho missionário visava ao combate dos inimigos da alma, tidos como o obstáculo para a realização das boas obras e como responsáveis pela destruição dos desígnios de Deus.

Na parábola, o mundo representa os falsos prazeres e as mentiras. No Catecismo Kiriri, eles são apresentados como as antigas práticas que deveriam ser abandonadas. Para alcançar a salvação, o índio deveria seguir os caminhos apresentados pelo missionário, a fim de conseguir passar "pela porta estreita", que o levaria a amar a Deus mais do que ao mundo. Caberia a eles deixar de lado os deleites humanos e seguir as leis do espírito e, por isso, ensinar a doutrina era tão importante, para "deixar o passado" e para "lavar a alma" (MAMIANI,1698, p. 162).

Para Mamiani (1698, p. 18), "ensinar os ignorantes" era obra da misericórdia e consistia em uma das virtudes do trabalho espiritual. Negar esse ensinamento tornava a pessoa

\footnotetext{
${ }^{14}$ Evangelho de Jesus Cristo segundo São Marcos (Marcos 4, 1-9).
} 
pecadora, pois "Peccaõ por ventura os pays, ou as máys, ou os senhores, \& pays de família não ensinando a doutrina aos seus filhos, escravos, \& súbditos" (MAMIANI,1698, p. 33). Todas as alegorias que o jesuíta utiliza remetem à necessidade de o índio abandonar as práticas ancestrais e estão relacionadas com o tema da limpeza e, consequentemente, da água do bastismo, sacramento admnistrado a todos os que rompessem com as antigas práticas.

A percepção e a proposição de Mamiani são distintas das do capuchinho Bernardo de Nantes, que refere constantamente à necessidade de "castigar os ignorantes" e de afastamento em relação aos que não seguiam os preceitos e não abandonavam as antigas práticas: "Não tomeis amizade com os mãos: fugi dos que são torpes, \& deshonestos: fechai os ouvidos ás palavras, \& cantigas deshonestas, \& supersticiosos dos Pagãos: os que são modestos, prudentes, \& tementes a deos, sejaõ vossos amigos (NANTES, 1896, p. 113).

Abandonar os amigos "pagãos", como recomendado, implicava romper com relações sociais instituídas e com práticas culturais, o que tornava ainda mais difíceis as mudanças pretendidas pelos missionários, como se constata nesta passagem do capuchinho Bernardo de Nantes:

Eu vos deixo livre, diz o Padre: Ego te absolvo; porq os peccados são huas correntes, que nos tem cativos: os peccados de furto, de mentira, de bebedice, de luxuria, são algemas com que o demônio amarrra aos Christão como seus escravos; mas o Sacerdote dando a absolvição, os desata. Direis tal vez: E o Sacerdote tem poder para tanto? Tem, não de si, mas de Deos que lhe deu este grande poder por estas palavras: Quadcupque solveitis, erit solutum \& in Caelis; não o deu a outro qualquer que for, Capitão, Governador, ou Rey, não tem estes poder para isto [...] (NANTES, 1896, p. 330).

Para frei Bernardo de Nantes, a batalha contra as "prisões do pecado" deveria ser uma prática diária, prever o controle das relações de amizade e da organização familiar e assegurar o respeito e a obediência à autoridade. Por isso, o estranhamento de Nantes em relação ao controle que as mulheres Kiriri exerciam sobre seus maridos e à ausência de castigos na educação dos filhos, o que segundo ele tornava o ambiente da aldeia propício ao descontrole. Já seu companheiro de missão, Martinho de Nantes, descreveu os indígenas da aldeia de Uracapá desta maneira: 
Foram mesmo com os seus louvores, até o ponto de dizerem da aldeia de Uracapá que ela parecia mais um convento de religiosos disciplinados do que uma assembleia de cristãos leigos, principalmente por causa da assiduidade à igreja e de sua inteira obediência ao padre missionário, que era como a de filhos bem nascidos para com os seus pais e suas mães. (NANTES, 1979, p. 19).

Como se pode observar, ambos nos oferecem detalhados registros etnográficos sobre os grupos indígenas dos sertões, que se somam às descrições que Mamiani fez das práticas culturais Kiriri a que temos acesso no Catecismo e na Gramática. Os três religiosos vêem "obstáculos" ao processo de conversão, mas têm percepções e proposições diferentes em relação às estratégias a serem adotadas. Para Mamiani, havia a necessidade de fortalecimento das três virtudes teológicas, a esperança, a caridade e a fé (MAMIANI, 1698, p. 15). Para ele, os indígenas deveriam crer, esperar e amar, e, assim, trilhar o caminho dos filhos de Deus:

Meu filho, não he bem que sigas os costumes dos vossos avós, porque se os seguirdes não podereis hir para o Ceo a gozar de Deos; somente o fogo do inferno será a vossa morada para sempre. Por tanto entendei bem o que vos digo, \& crede o que vos ensino, para que sejais filho de Deos Se assim fizerdes, hireis para o Ceo a gozar a bem-aventurança. (MAMIANI, 1698, p. 156).

No Catecismo, mais do que apontar para a necessidade do abandono das práticas dos "costumes dos vossos avós", Mamiani chama a atenção para as condutas que assegurariam a bem-aventurança. De acordo com o jesuíta, os bem-aventurados eram "os pobres de espírito, porque delles he o reyno do Ceo"; os mansos que "possuirão a terra"; os que choram, "porque serão consolados"; os que tem fome e sede de justiça "porque serão consolados"; os que usam da misericórdia "porque eles alcançaram misericórdia"; os limpos de coração "porque elles verão a Deos nosso Senhor"; os pacíficos "porque elles seão chamados filhos de Deos" e os que padecem de perseguição “porque delles he o Reyno do Ceo" (MAMIANI, 1698, p. 19).

Para alcançar a bem-aventurança, os indígenas deveriam abandonar seus cultos e a doutrina deveria lhes ser explicada de forma clara, de forma que, por exemplo, eles não adorassem a materialidade dos santos, mas o que eles representavam: "não adoro o pão, a pedra, ou o barro; mas unicamente adoro aos Santos figurados naquellas imagens de pão, de pedra \& de barro" (MAMIANI, 1698, p. 31). 
No Catecismo de Bernardo de Nantes, encontramos a referência ao deus Politão, apresentando-o como "falso deus" que proferia "mentiras", razão pela qual instava os índios a abraçarem o Deus cristão por meio do batismo: ${ }^{15}$

O vosso antigo Deos Politão, que tinheis por hum ermosissimo mancebo, he hum Deos falso: cuidáveis que ele tinha o poder de vos depara a caça, de vos fazer afortunados para a pescaria, nhão ha tal. Tomastes hum por outro, Politão por Jesu Chisto: elle he que verdadeiramente vos faz afortunados, \& venturosos; porque elle vos deparou as grandes delicias, \& riquezas do Ceo. Politão vos fazia levar a sua marca do batoque nos beiços, que elles vos mandava furar com sensíveis dores em sinal de vossa escravidão. Mas Jesu Christo sem vos causar dor, pelo sacramento do santo Bautismo vos marca por seus filhos, \& vos põe em liberdade (NANTES, 1896, p. 212).

Na passagem abaixo, além da menção feita ao apóstolo São Tomé, encontramos o registro da tentativa de explicação da Santíssima Trindade, através da referência que o frei capuchinho faz aos deuses Badze, Politan e Wanagnwidze: ${ }^{16}$

Devião vossos antepassados ter algua notícia do mysterio da Santissima Trindade, \& pode ser $\mathrm{q}$ o Apostolo $\mathrm{S}$. Thome lhes teria pregado; mas ou por esquecimento, ou plea distancia dos tempos, lhe misturarião erros, porque bem sabeis, que q elles admittião tres deoses, deos Badze, deos Politan, \& deos Wanagnwidze: o primeiro davao o nome de padzu, que quer dizer Padre: ao segundo o nome de Inhura, que quer dizer Filho; \& ao terceiro o nome de Irandè, que quer dizer Companheiro, ou amigo dos dous. Estes são huns arremedos das tres Pessoas da Santissima Trindade,

\footnotetext{
${ }^{15} \mathrm{~B}$. Nantes reforça a importância do batismo para o abandono das antigas práticas e dele para ascender aos céus, como proposto por Peña Montenegro, sobre o qual tratamos no capítulo anterior: "Y que la necessidade en que están estos Indios que he dicho, sea extrema, es cosas manifesta, por estar en riesfo de perder la vista de Dios, como de hecho la pierden muchos nifios, que no tuvieron dicha de vivir hasta que à los sis meses entrase el Cura à bautizarlos: y todos los adultos que mueren sin confesion, ni otros Sacramentos, haviendo vivido sin Fé, sin instruccion, sin Sacramentos: siendo pues evidente, que es necessidad espiritual extrema, es tambien consequência clara, que pena de pecado mortal estan obligados, à buscar y poner todos los medios posibles para el remédio de daños tan graves, despues tan irremediables." (PEÑA MONTENEGRO, 1678, p. 81).

${ }^{16}$ Sabe-se que os Payayá, que habitavam uma região próxima daquela em que viviam os Kiriri, cultuavam outros dois deuses, que possuíam também uma estreita relação com elementos da natureza importantes para os índios que viviam nos sertões: "De Arachizá e Poditá, dois irmãos do gênero dos Tapuias que moravam em Orion, esperavam chuvas, alimentos e a vitória certa sobre os inimigos. Junto a eles não havia nenhuma outra notícia de Deus imortal, cuja existência não afirmavam, nem negavam. Tinham o nome do Espírito do Mal (Daemon Mail), mas ignoravam quem fosse e de onde tirasse as artes de fazer o mal." Annuae Littere ex Brasilia anno 1683, ARSI, Bras 9, f. 383.
} 
que conheciao confusamente, \& vós agora pela grade de Deos distinatamente semerro (NANTES, 1896, p. 176).

Como já destacamos, Mamiani, diferentemente de B. de Nantes, recorreu a elementos da natureza para explicar Santissima Trindade e os demais "mistérios da fé", (MAMIANI, 1698, p. 43) mas não deixou de fazer referência aos deuses Kiriri quando relatou suas festas: 0 Vuankdzan, cuja grafia muda bastante nos registros, e Potidzan, que poderia ser Politan, referidas também por outros missionários jesuítas que o antecederam na região.

Cabe ressaltar que estas passagens, mais do que seu conteúdo etnográfico, nos revelam também as percepções dos missionários sobre as denominadas práticas de "gentilidade", e que, de acordo com o que estava estabelecido no Concílio de Lima e ratificado no "Itinerario para Parochos de Indios" (PEÑA MONTENEGRO, 1678, p. 284), eles tinham a obrigação de reportar os casos aos Superiores e castigar os índios por tais práticas.

Los Indios que hazen superticones, y ceremonias, y ritos diabólicos, mayormente para tomar aguero de los negócios que comiençan, y hazen ceremonias en los entierros de sus defuntos, si se hallaren permanecen en los ritos de su Gentilidad (PEÑA MONTENEGRO, 1678, p. 284).

"Enterrar os mortos" e "rogar a Deus pelos vivos, \& defuntos", são obras da Misericórdia, como exposto por Mamiani, sendo que a primeira está relacionada com as obras do corpo, e a segunda, com as obras do espírito. (MAMIANI, 1698, p. 17). Para o gentio, o jesuíta ensina que, após a morte, o corpo fica enterrado na sepultura, mas a alma, eterna, poderia ir a três lugares, dependendo das ações praticadas em vida. Os bons teriam lugar no céu e viveriam felizes com Deus; (MAMIANI, 1698, p. 81). Os que não tivessem vivido inteiramente segundo a vontade de Deus iriam para o purgatório, localizado logo acima do inferno.(MAMIANI, 1698, p. 101). Por fim, os pecadores iriam para o inferno, (MAMIANI, 1698, p. 70) "[...] os máos hirão ao inferno em corpo, \& alma, para padecerem hum, \& outra tormentos eternos em companhia do diabo." (MAMIANI, 1698, p. 160). Mamiani ainda reitera que seguir os "costumes dos vossos avós" só iria levá-los ao inferno. (MAMIANI, 1698, p. 157).

O jesuíta, no entanto, descreveu quatro moradas para alma no centro da terra: "o inferno, o purgatório, o limbo dos meninos e o limbo dos santos padres" (MAMIANI, 1698, p. 53). O limbo dos meninos era uma caverna escura localizada acima do purgatório, onde ficavam os meninos que haviam morrido sem o batismo, e o limbo dos padres, para onde antigamente iam as almas dos padres, antes da morte de Cristo. Já o inferno era descrito como uma grande 
fogueira, "hum incêndio de fogo inextinguivel aonde ardem deveras" (MAMIANI, 1698, p. 53), para a qual todos os não cristãos eram levados, bem como aqueles que não seguiam as normas determinadas pelos padres. Esses pecadores teriam seu corpo queimado por toda a eternidade:

M. Que dirá JESU Christo aos que achar em peccado?

D. Dirá: Apartivos de mim todos para o fogo eterno, que esta aparelhado por Deos há muito tempo para castigo das maldades, assim do diabo, como dos seus sequazes. Então se abrirá a terra para serem lançados todos no inferno. (MAMIANI, 1698, p. 68).

Como podemos observar, o controle e o combate aos "costumes dos avós" se fazia presente na trama do cotidiano das aldeias, se impondo sobre o tempo ordinário e também sobre o tempo sagrado, o tempo das celebrações e dos rituais de sepultamento. Essas antigas práticas eram um obstáculo à conversão, pois se encontravam atreladas aos pecados do mundo. Havia a necessidade de abandonar as práticas tradicionais. Elas, contudo, não eram o único empecilho, no próximo tópico, nos detemos em mais um dos "inimigos da alma".

Após a Visita realizada pelo padre Antônio Vieira à região, as festas "profanas" foram modificadas e passaram a integrar o calendário litúrgico adotado pelos jesuítas. $\mathrm{O}$ mesmo pode ser observado em relação aos capuchinhos, como se pode constatar neste trecho extraído da Relação de Bernardo de Nantes:

Para tirar aos poucos deles, sem impedir de se divertirem, o costume que tinham antigamente, de celebrar festas supersticiosas e diabólicas, nos opomos apenas às que eram más, mudando o motivo delas. Asism, os banquetes que faziam em louvor de seus falsos deuses, Politim ou Uranqquidzé, eles fazem hoje religiosamente em louvor dos santos de que levam o nome (NANTES apud POMPA, 2003, p. 406).

Os missionários adotaram as recomendações de Vieira e as tradicionais festas deram lugar a outras. No Catecismo de Mamiani é possível observar esse tempo festivo, a partir de duas concepções de tempo, o sagrado e o profano, que se manifestam tanto nas práticas diárias de cada sujeito, quanto nas coletivas e voltadas para o bem comum do grupo. Observase que no tempo profano, há um conjunto maior de práticas particulares, constituídas pelas orações individuais e por modelos de conduta que deveriam ser seguidos. Contudo, a salvação, 
e isto Mamiani fez questão de reiterar, não era alcançada apenas através de ações individuais, razão pela qual as praticadas com e para o outro também deviam ser ensinadas e orientadas para a bem-aventurança. (ELIADE, 2001, p. 63).

O tempo ordinário era rompido pelo tempo sagrado (ELIADE, 2001) dos domingos, do primeiro dia das festas do Nascimento do Senhor, da Ressurreição, Pentecostes, das festas da Circuncisão, da Epifania, da Ascensão, de Corpus Christi, do Nascimento do Senhor, da Purificação, da Anunciação, da Assunção, como, também, do dia de São Pedro e São Paulo. (MAMIANI, 1698, p. 89). Esses eram os dias santos específicos, nos quais os índios eram obrigados a guardar o dia e ouvir a missa, como reforçava Peña Montenegro:

El Concilio Tridentino en la sess.13. cp. I de Eucharistia, y Cn. I. \& 3. dice, que la Misa es el verdadeiro Sacrificio que á Dios se le oferece en su Iglesia, y el perfecto y agradable, que japás se le ofreció, ni se le pudo oferecer: y que este es el próprio oficio del Sacerdote; y que para este particular y senaladamente le dá la Iglesia el Orden y postestad del Sacerdocio, en virtude del qual se le imprimi aquel caracter o senal espiritual: y para que dignamente pueda ofrecerle, recibe por la vitud y eficácia de este Sacramento del Orden, ex opere operato, gracias espiritual, y justamente otros dones y virtudes (PEÑA MONTENEGRO, 1771, p. 79).

No quadro abaixo, aparecem relacionadas as festas do calendário litúrgico, conforme as obras de Antônio Araújo, Luigi Mamiani e Bernardo de Nantes e, também, de acordo com as Constituições Primeiras do Arcebispado da Bahia. Cabia aos padres ensinar e comunicar os índios sobre as referidas celebrações:

Quadro 1 - Festas que os Índios eram obrigados a guardar e respeitar

\begin{tabular}{|l|l|l|ll|}
\hline ANTÕNIO ARAÚJO & MAMIANI & BERNARDO NANTES & $\begin{array}{l}\text { CONSTITUIÇÕES } \\
\text { PRIMEIRAS }\end{array}$ \\
\hline
\end{tabular}




\begin{tabular}{|c|c|c|c|}
\hline $1^{\mathrm{A}}$. EDIÇÃO ${ }^{17}$ & & & $\begin{array}{l}\text { ARCEBISPADO DA } \\
\text { BAHIA }\end{array}$ \\
\hline $\begin{array}{l}\text { 1. Circuncisão de } \\
\text { Jesus } \\
\text { 2. Domingo da } \\
\text { Epifania } \\
\text { 3. São Sebastião } \\
\text { 4. Virgem da } \\
\text { Purificação } \\
\text { 5. São Matthias o } \\
\text { Apostolo } \\
\text { 6. Anunciação } \\
\text { 7. Paixão de Cristo } \\
\text { 8. Ressureição } \\
\text { 9. Guarda da Virgem } \\
\text { Maria } \\
\text { 10. Ascenção } \\
\text { 11. Pentecostes } \\
\text { 12. Santissima } \\
\text { Trindade } \\
\text { 13. Corpus Christi } \\
\text { 14. Apóstolo Felipe e } \\
\text { Jacob } \\
\text { 15. Invenção da Santa } \\
\text { Cruz } \\
\text { 16. Santo Antônio } \\
\text { 17. Nascimento de São } \\
\text { João Batista } \\
\text { 18. São Pedro e Paulo } \\
\text { 19. Visitação de Santa } \\
\text { Isabel } \\
\text { 20. São Tiago o } \\
\text { Apostolo } \\
\text { 21. Nossa Senhora das } \\
\text { Neves } \\
\text { 22. São Lourenço } \\
\text { Márti } \\
\text { 23. Assunção da } \\
\text { Virgem } \\
\text { 24. São Bartholomeu } \\
\text { Apostolo } \\
\text { 25. Nascimento Nossa } \\
\text { Senhora } \\
\text { 26. Matheus Apostolo } \\
\text { 27. São Miguel o } \\
\text { Arcanjo } \\
\text { 28. São Judas Tadeu } \\
\text { 29. Festa Todos os } \\
\text { Santos } \\
\text { 30. Dia de Finados André Apostolo } \\
\text { 31. Apresentação N. } \\
\text { 32. Anora ao Templo } \\
\text { ando }\end{array}$ & $\begin{array}{l}\text { 1. Todos os domingos } \\
\text { 2. O primeiro dia das } \\
\text { festas de Nascimento } \\
\text { do Senhor } \\
\text { 3. Da Resurreição } \\
\text { 4. De Pentencoste } \\
\text { 5. A festa da } \\
\text { Circuncisão } \\
\text { 6. A festa da } \\
\text { Epiphania } \\
\text { 7. A festa da } \\
\text { Ascenção } \\
\text { 8. A festa de Corpus } \\
\text { Christi } \\
\text { 9. A festa do } \\
\text { Nascimento de } \\
\text { Nossa Senhora } \\
\text { 10. Da Purificação } \\
\text { 11. Da Anunciação } \\
\text { 12. Da Assupção } \\
\text { 13. O dia dos } \\
\text { Apostolos S. Pedro e } \\
\text { S. Paulo }\end{array}$ & $\begin{array}{l}\text { 1.Todos os domingos } \\
\text { 2. A festa de Natal } \\
\text { 3. A festa da } \\
\text { Circuncisão } \\
\text { 4. A festa de Reys } \\
\text { 5. A primeira oytava } \\
\text { da Pascoa } \\
\text { 6. A festa da Ascensão } \\
\text { 7. A primeira oytava } \\
\text { do Espirito Santo } \\
\text { 8. A festa do Corpo de } \\
\text { Deos } \\
\text { 9. A festa da } \\
\text { Annunciação de N. } \\
\text { Senhora } \\
\text { 10. A festa da } \\
\text { Purificação } \\
\text { 11. A festa da } \\
\text { Assumpsão de Nossa } \\
\text { Senhora } \\
\text { 12. A festa da } \\
\text { Natividade de Nossa } \\
\text { Senhora } \\
\text { 13. A festa de S. Pedro } \\
\text { e de S. Paulo }\end{array}$ & $\begin{array}{l}\text { 1. Todos os domingos } \\
\text { 2. Circuncisão de } \\
\text { Jesus cristo } \\
\text { 3. A Epiphania } \\
\text { 4. A Purificação } \\
\text { 5. São Mathias } \\
\text { 6. São José } \\
\text { 7. Anunciação de } \\
\text { Nossa Senhora } \\
\text { 8. São Felipe e } \\
\text { Santiago Apostolos } \\
\text { 9. Invenção da Santa } \\
\text { Cruz } \\
\text { 10. Santo Antonio } \\
\text { 11. O nascimento de } \\
\text { São João Batista } \\
\text { 12. São Pedro e São } \\
\text { Paulo Apostolos } \\
\text { 13. Santiago Apostolo } \\
\text { 14. Sant'Anna } \\
\text { 15. São Lourenço } \\
\text { 16. Assumpção da } \\
\text { Virgem } \\
\text { 17. Bartlholomeo } \\
\text { Apostolo } \\
\text { 18. Nascimento da } \\
\text { Virgem } \\
\text { 19. São Matheos } \\
\text { Apostolo } \\
\text { 20. Dedicação de São } \\
\text { Miguel Arcanjo } \\
\text { 21. São Simão e São } \\
\text { Judas Apostolos } \\
\text { 22. A festa de todos os } \\
\text { Santos } \\
\text { 23. Santo André o } \\
\text { Apóstolo } \\
\text { 24. Nossa Senhora da } \\
\text { Conceição } \\
\text { 25. São Francisco } \\
\text { Xavier } \\
\text { 26. São Thomé o } \\
\text { Apostólo } \\
\text { 27. O nascimento do } \\
\text { Senhor Jesus Christo } \\
\text { 28. Santo Estevão } \\
\text { 29. São João o } \\
\text { Apostolo e } \\
\text { Evangelista } \\
\text { 31. Santos Inocentes } \\
\text { 32. São Silvestre } \\
\text { 19umo }\end{array}$ \\
\hline
\end{tabular}

${ }^{17}$ Convém ressaltar que na segunda edição do Catecismo do padre Antonio Araújo as festas não aparecem relacionadas da mesma forma que na primeira, sendo apresentadas na ordem dos meses em que eram realizadas. 


\begin{tabular}{|l|l|l|}
\hline $\begin{array}{l}\text { 33. Nossa Senhora da } \\
\text { Conceição }\end{array}$ & & 33. Domingo de \\
34. São Tomé & & $\begin{array}{l}\text { Pascoa (a segunda e a } \\
\text { terça feira seguintes) } \\
\text { 35. Nascimento de } \\
\text { Cristo }\end{array}$ \\
36. Santo Estevão & & 34. Quinta-feira da \\
& & Ascenção do Nosso \\
& & Senhor \\
& & 35. Dia do Espírito \\
& & Santo \\
& & 36. Corpus Christi \\
\end{tabular}

Fonte: Elaborado pela autora.

Ao observarmos as festas elencadas pelo jesuíta italiano, constata-se que eram apenas treze, número bastante inferior as que foram relacionadas pelos demais religiosos e pelas Constituições Primeiras, de 1707. Vale lembrar que, de acordo com Mamiani, tanto nos domingos, como no dias santos se devia ouvir a missa ${ }^{18}$ e rezar, sendo permitido cozinhar, comer, caçar e pescar.

A primeira edição do Catecismo de Araújo observa as datas propostas nas Constituições do Arcebispado de Lisboa, ${ }^{19}$ que previa os dias em que era obrigado jejuar, como na sexta-feira da Quaresma, na Vigilia de Natal e na Ressureição (MAMIANI, 1698, p. 105). Nos outros dias, bastava apenas não comer carne, com base na concessão do Papa Paulo III. As mesmas orientações se encontram no Catecismo de Bernardo de Nantes, havendo apenas uma alteração de nomenclatura, pois o capuchinho refere-se ao jejum no Sábado Santo e não na Ressureição. (NANTES, 1896). Além disso, matrimônios ou qualquer outro tipo de comemoração não poderiam ocorrer no período do Advento e na Quaresma (MAMIANI, 1698, p. 204):

Antes todas cosa tenga muy en la memoria el Cura de Indios lo que disse Reginaldo, I. p. 1.4. cap. 17 con Navarro, y Azor, los quales aconsejan, que el Parocho se incline mas a dispensar con. Piedad, que a negarla com escrúpulos [...] Esta doctrina general tiene mas lugar en los Indios, que en los Españoles, orque su pobreza, su trabajo, desnudez, y hãbre estanta, que con lo que un Indio comeen quatro dias, no se atreviera a aynnar ninguno de nossotros un dia, y si aynara, fuera muy buena mortificacion, y pues Paulo III, de felice recordacion, informado de la

\footnotetext{
${ }^{18}$ Realizar missas pela manhã era também o que estava estabelecido nas Constituições Primeiras do Arcebispado da Bahia, celebrado no dia 12 de junho de 1707, no Título IV: "Em que tempo, hora, e lugar se deve dizer a Missa, artigo 336: Prohibe o Sagrado Concilio Tridentino, que os Sacerdotes digão Missa fora das horas devidas, e competentes, as quaes conforme o costume universal da Igreja, e Rubricas do Missal Romano, são desde que rompe a alva até o meio dia". (VIDE, 2007, p. 137).

${ }^{19}$ Constituições do Arcebipado de Lisboa. Assi as antigas como as extravagantes primeyras \& segundas. Agora novamente impressas por mandado do Illustrismo \& Revendissimo Senhor dõ Migel de Castro Arcebispo de Lisboa. Lisboa: Belchio Rodrigues, 1588, p. 21.
} 
pobreza, y trabajo de los Indios, les concediò, que no tengan obligacion de ayunar por precepto, sino solto los Viernes de Quaresma, y el Sabado Santo, y la vigília de Navidad, y que en los dichos dias puedan comer qualesquiera manjares de los que son conceidos a los que toman la Bula de la Santa Cruzada [...] (PEÑA MONTENEGRO, 1678, p. 144).

Ao lermos o "Itinerário dos Parócos dos Índios", obra que, como já observamos, forneceu a fundamentação do direito canônico para o Catecismo de Mamiani, encontramos a referência que seu autor Peña Montenegro faz às dispensas que podiam ser concedidas aos índios:

La razon en que me fundo es que Urbano VIII en una Bula que concedió a los Padres de la Compañia de Jesus, de que haré mencion mas de proposito, para poder dispensar con los Indios en todos los grados que no estan prohibidos por Derecho Divino, y para remitir las denunciaciones, les pone por condicion, que esto puedan hacer in wroque foro, como estén en partes muy distantes, remotas, y apartadas de los Obispos. (PEÑA MONTENEGRO, 1678, p. 592).

A legislação eclesiástica vigente no período previa que "miseráveis", "pobres" "menores" e "rústicos", mesmo não atendendo a todas as condições necessárias para a confissão, podiam ser absolvidos. (PEÑA MONTENEGRO, 1678, p. 216). Essa pode ser a explicação para o fato de Mamiani reiterar em seus escritos que os índios não eram obrigados a responder a todas as perguntas, nem seguir todas as exigências contidas nas Constituições do Arcebispado de Lisboa, como se pode constatar nesta passagem extraída do Catecismo:

[...] Nos outros dias Santos podem trabalhar por concessão de hua Bulla de Paulo III. Porém nestes dias Santos em que podem trabalhar são obrigados a ouvir Missa, porque os preceitos de ouvir Missão, \& de não trabalhar, são diversos, \& dispesando o Pontifice em um, não se segue a dispensa no outro (MAMIANI, 1698, p. 89).

Quanto à questão do trabalho nos dias santos, Mamiani ressalta que, em decorrência da Bula de Paulo III, do ano de 1537, não apenas os indígenas estavam dispensados das atividades 
ordinárias, como reiterava-se a importância de não privá-los de sua liberdade para assegurar que fossem "atraídos e convidados à Fé de Cristo":

\begin{abstract}
Nós outros, pois, que ainda que indignos, temos as vezes de Deus na terra, e procuramos com todas as forças achar suas ovelhas, que andam perdidas fora de seu rebanho, pera reduzi-las a ele, pois este é nosso oficio; conhecendo que aqueles mesmos Indios, como verdadeiros homens, não somente são capazes da Fé de Cristo, senão que acodem a ela, correndo com grandissima prontidão, segundo nos consta: e querendo prover nestas cousas de remédio conveniente, com autoridade Apostólica, pelo teor das presentes letras, determinamos, e declaramos, que os ditos Indios, e todas as mais gentes que daqui em diante vierem à notícia dos Cristãos, ainda que estejam fóra da Fé de Cristo, não estão privados, nem devem sê-lo, de sua liberdade, nem do dominio de seus bens, e que não devem ser reduzidos a servidão. Declarando que os ditos índios, e as demais gentes hão de ser atraídas, e convidadas à dita Fé de Cristo, com a pregação da palavra divina, e com o exemplo de boa vida. ${ }^{20}$ (MONTFORT ASSOCIAÇÃO CULTURAL, 2016, grifo nosso)
\end{abstract}

A comunhão na Quaresma, na Páscoa e nas oitavas de Corpus Christi era obrigatória, de acordo com Mamiani: "Concedeo o Papa Urbano VIII aos Indios, \& Negros da América, que possão satisfazer a este preceito desde o principio da Quaresma até a Sexta de Corpus Christi com toda a sua Octava." (MAMIANI, 1698, p.103). Para fundamentar esta orientação, o jesuíta buscou embasamento na Commissum Nobis, de 24 de abril de 1639, (HERNAEZ, 1879) que estabeleceu a excomunhão daqueles que escravizassem índios, e que provocou uma série de manifestações contra os jesuítas no Maranhão, Rio de Janeiro e São Paulo:

Fazemos saber que a santidade do Papa Urbano oitavo nosso senhor ora na Igreja de Deus Presidente, passou hum Breve sub annulo Piscatoris dado em Roma aos vinte dous de Abril deste presente anno de mil seiscentos trinta e nove [...] Urbano Papa oitavo. Amado filho saude e Apostolica benção. O Ministerio do officio do supremo Apostolado a Nos comettido pello Senhor, pede que parecendonos estar a nosso cargo a salvação de todos, naão somente para com os Fieism mas tambem para com aquelles que qainda estão fora do gremio da igreja nas trevas da

\footnotetext{
${ }^{20}$ Papa Paulo III. Bula Veritas Ipsa. 9 de junho de 1537.
} 
pagam supertiçaõ, mostremos effeitos de nossa parternal caridade e procuremos quanto podemos em o Senhor, tirarlhes aquellas cousas que de qualquer modo lhes podem servir de obstaculo quando saò trazidos ao conhecimento da Fé e verdade christam.(BREVE..., 2006, p. 569)

Ao apresentar os cinco mandamentos da Igreja, Mamiani reiterou as obrigações do bom cristão, não deixando, contudo, de salientar as exceções a que os índios tinham direito. Para o jesuíta, a missa, dentre todas as obrigações cotidianas, era uma forma de louvar a Deus, um momento que "se oferece o Filho de Deos debaixo das espécies do pão, \& do vinho" no intuito de conceder alguma graça e também se oferece o sangue e o corpo de Cristo na "satisfação dos nossos pecados" (MAMIANI, 1698, p. 100).

Em alguns casos, não era pecado se os índios não fossem à missa: quando fosse comprovada a ausência de padres, quando estivessem presos, se se encontrassem doentes ou em lugares distantes da aldeia, quando os senhores não os autorizassem a participar da missa ou quando estivessem encarregados de cuidar de um doente. Aqui, o jesuíta chama atenção para uma questão importante: a continuidade do trabalho da conversão só era possível com a presença de padres junto aos aldeamentos, daí, a necessidade de manter os índios próximos das aldeias, a fim de que pudessem comparecer às celebrações.

\section{Considerações finais}

Ao destacar as práticas e condutas condenáveis, Mamiani aponta os caminhos que deveriam ser adotados para a edificação das boas obras. Para isso, ele estabelece quatro pontos, que consistiam nos elementos considerados fundamentais para a catequese dos Kiriri, que, além de abandonar as festas e as danças próprias dos Tapuia, deveriam deixar de invocar o demônio e de acreditar na capacidade de cura dos feiticeiros. Deveriam se dedicar aos "Artigos da Fé", aos "Mandamentos da Ley de Deus" e observar os "sacramentos", para, desta forma, combater os inimigos da alma. De acordo com Mamiani, o batismo e o matrimônio auxiliavam nas questões da carne, a eucaristia e a extrema unção controlavam a ação do demônio e a penitência servia para afastá-los dos prazeres do mundo. Para que o zelo fosse constante, os indígenas deveriam se "benzer muitas vezes", "para que Deos nos livre dos nossos inimigos, mundo, Diabo, \& Carne”. (MAMIANI, 1698, p. 30) Como se pode perceber, no Catecismo, Mamiani expôs os "maus costumes" e apresentou os caminhos para a "instrução dos İndios", 


\section{Referências}

AGNOLIN, Adone. Jesuitas e selvagens: a negociação da fé no encontro catequético-ritual americano-tupi (sec. XVI-XVII). São Paulo: Humanitas Editorial, 2007.

ALMEIDA, Maria Celestino de. Os índios na história do Brasil. Rio de Janeiro: FGV, 2010.

BANDEIRA, Maria de Lourdes. Os kariris de mirandela: um grupo indígena integrado.. Salvador: Universidade Federal da Bahia, 1972. (Série Estudos Baianos, n. 6).

BREVE do Papa Urbano VIII, "Commissum Nobis", de 22 de Abril de 1639, sobre a Liberdade dos Índios da América. In: LEITE, Serafim. História da Companhia de Jesus. 6 v. Belo Horizonte: Editora Itatiaia, 2006. p. 569

CASTELNAU-L'ESTOILE, Charlotte de. Operários de uma vinha estéril. Tradução de Ilka Stern Cohen. Bauru: EDUSC, 2006.

CHAMBOULEYRON, Rafael. Justificadas e repetidas queixas: o Maranhão em revolta (século XVII). Disponível em: $\underline{\text { http://cvc.instituto- }}$ camoes.pt/eaar/coloquio/comunicacoes/rafael_chambouleyron.pdf $>$. Acesso em: 16 set. 2015.

DANTAS, Beatriz Góis. Missão indígena no Geru. Aracaju: UFS, 1973.

ELIADE, Mircea. O sagrado e o profano: essência das religiões. Tradução de Rogério Fernandes. São Paulo: Martins Fontes, 2001.

FONSECA, Maria Cecilía Londres. O patrimônio em processo: trajetória da política federal de preservação no Brasil. Rio de Janeiro: UFRJ/Minc-IPHAN, 2005.

FREIRE, Felisbelo. História de Sergipe. 2. ed. Petrópolis: Vozes; Aracaju: Governo do Estado de Sergipe, 1977.

HARTOG, François. Memória de Ulisses: narrativas sobre a fronteira na Grécia antiga. Tradução de Jacyntho Lins Brandão. Belo Horizonte: UFMG, 2004.

HERNAEZ, F. J. Colleccion de bulas, breves y otros: documentos relativos a la Iglesia de América y Filipinas, 1879, v. 1, p. 109-110. 
LEITE, Serafim. História da companhia de Jesus no Brasil. Rio de Janeiro: Imprensa Nacional, 1945. t. 5.

LEITE, Serafim. História da companhia de Jesus no Brasil. São Paulo: Loyola, 2003. t. 5.

LEITE, Serafim. História da companhia de Jesus. São Paulo: Loyola, 2004. v. 8.

MAMIANI, Luiz Vincêncio. Arte de grammatica da lingua brasilica da naçam kiriri. 2. ed. Rio de Janeiro: Biblioteca Nacional, 1877.

MAMIANI, Luiz Vincêncio. Catecismo da doutrina christãa na lingua brasilica da nação kiriri. Rio de Janeiro: Biblioteca Nacional, 1942.

MAMIANI, Luiz Vincêncio. Catecismo da Doutrina christãa na lingua brasilica da nação kiriri. Lisboa: Deslandes Impresso Régio, 1698.

MARIANI, Bethania. Colonização linguística: línguas, política e religião no Brasil (século XVI a XVIII) e nos Estados Unidos da América (século XVIII).Campinas: Pontes, 2004.

MONTFORT ASSOCIAÇÃO CULTURAL. Bula Veritas Ipsa. Disponível em: $<$ http://www.montfort.org.br/bra/documentos/decretos/veritas_ipsa/>. Acesso em: $26 \mathrm{dez}$. 2016.

NANTES, Bernardo de. Catecismo da lingua kariris, acrescentado de várias praticas doutrinaes e Moraes, adaptadas ao gentio e capacidade dos Indios do Brasil. Leipzig: Edicção fac-similar, 1896.

NANTES, Martinho, Relação de uma missão no Rio São Francisco. 2. ed. São Paulo: Editora Nacional, 1979.

NUNES, José Horta. Dicionários no Brasil: análise e história do século XVI ao XIX. Campinas: Pontes, 2006.

NUNES, Maria Thetis. Sergipe colonial II. Rio de Janeiro: Tempo Brasileiro, 1996.

PEÑA MONTENEGRO, Alonso de la. Itinerario para párrocos de indios. 2. ed. En Leon de Francia: Huguenta y Compañia, 1678.

PEÑA MONTENEGRO, Alonso de la. Itinerario para párrocos de indios. Madrid: En la Oficina de Pedro Marin, 1771.

POMPA, Cristina. Religião como tradução: missionários, tupi e "tapuia" no Brasil colonial. Bauru: EDUSC, 2003. 
RUSSEL-WOOD, A. J. R. O Brasil colonial: o ciclo do ouro, c. 1690-1750. In: BETHEL, Leslie (Org.). América Latina colonial. São Paulo: Edusp; FUNAG, 1999. p. 475.

SANTANA, Pedro Abelardo. Aldeamentos indígenas em Sergipe colonial: subsídios para a investigação de arqueologia histórica. 2004. Dissertação (Mestrado em Geografia) Universidade Federal de Sergipe, São Cristóvão, 2004.

SANTOS, Fabricio Lyrio. Da catequese à civilização: colonização e povos indígenas na Bahia. Cruz das Almas: UFRB, 2014.

VIDE, Sebastião Monteiro da. Constituições primeiras do Arcebispado da Bahia: feitas e ordenadas pelo ilustríssimo e reverendíssimo D. Sebastião Monteiro da Vide. Brasília: Senado Federal, 2007.

ZERON, Carlos Alberto de Moura Ribeiro; VELLOSO, Gustavo. Economia cristã e religiosa política: o "Memorial sobre o governo temporal do colégio de São Paulo", de Luigi Vincenzo Mamiani. História Unisinos, São Leopoldo, v. 19, n. 2, p. 120-137, maio/ago. 2015.

Submetido em 21/03/2018

Aprovado em 16/05/2018 